\title{
Incidence and types of preventable adverse events in elderly patients: population based review of medical records
}

\author{
Eric J Thomas, Troyen A Brennan
}

\begin{abstract}
Objective To determine the incidence and types of preventable adverse events in elderly patients. Design Review of random sample of medical records in two stage process by nurses and physicians to detect adverse events. Two study investigators then judged preventability.

Setting Hospitals in US states of Utah and Colorado, excluding psychiatric and Veterans Administration hospitals.

Subjects 15000 hospitalised patients discharged in 1992.

Main outcome measures Incidence of preventable adverse events (number of preventable events per 100 discharges) in elderly patients ( $\geqslant 65$ years old) and non-elderly patients (16-64 years).

Results When results were extrapolated to represent all discharges in 1992 in both states, non-elderly patients had 8901 adverse events (incidence 2.80\% (SE 0.18\%)) compared with 7419 (5.29\% (0.37\%)) among elderly patients $(\mathrm{P}=0.001)$. Non-elderly patients had 5038 preventable adverse events (incidence 1.58\% (0.14\%)) compared with 4134 $(2.95 \%(0.28 \%))$ in elderly patients $(\mathrm{P}=0.001)$. Elderly patients had a higher incidence of preventable events related to medical procedures (such as thoracentesis, cardiac catheterisation) $(0.69 \%(0.14 \%) v 0.13 \%$ $(0.04 \%))$, preventable adverse drug events $(0.63 \%$ $(0.14 \%)$ v $0.17 \%(0.05 \%))$, and preventable falls $(0.10 \%$ $(0.06 \%)$ v $0.01 \%(0.02 \%))$. In multivariate analyses, adjusted for comorbid illnesses and case mix, age was not an independent predictor of preventable adverse events.

Conclusions Preventable adverse events were more common among elderly patients, probably because of the clinical complexity of their care rather than age based discrimination. Preventable adverse drug events, events related to medical procedures, and falls were especially common in elderly patients and should be targets for efforts to prevent errors.
\end{abstract}

\section{Introduction}

Data from the Harvard medical practice study and the Utah and Colorado medical practice study show that preventable adverse events in hospitalised patients are at least the eighth leading cause of death in the United States. ${ }^{1}$ The Harvard medical practice study also found that adverse events were more common among elderly patients. ${ }^{2}$ Several studies in single institutions have also suggested this may be true, but they have limited generalisability because of their reliance on data from one hospital. Given that the population of many countries is ageing, additional data to confirm these findings and to focus efforts to improve care would be useful. For example, the number of people in the United States aged 65 years and over will increase from 34.1 million in 1997 to 69.4 million in 2030 .
For this paper, we reanalysed data from the Utah and Colorado medical practice study ${ }^{4}$ in order to describe the incidence and types of preventable adverse events in elderly patients and the morbidity and mortality caused by these events in elderly compared with non-elderly patients.

\section{Methods}

A detailed description of the Utah and Colorado medical practice study can be found elsewhere. ${ }^{4}$

\section{Sampling strategy}

From a representative sample of hospitals, excluding psychiatric and Veterans Administration hospitals, we randomly sampled records of 5000 discharges in Utah and 10000 discharges in Colorado in the calendar year 1992. The number of records sampled in each hospital was proportional to the number of each hospital's discharges relative to the total discharges of all hospitals in the study.

\section{Record review}

Initially, 31 trained nurses reviewed the medical records for any one of 18 criteria associated with an adverse event. Records that were positive were referred to one of 22 local physicians (board certified family practitioners or internists) who were trained to use the adverse event analysis form. ${ }^{5}$ Since judgments about adverse events may be complex, we used a six point confidence scale. Specialist consultation was available for the reviewing physicians if requested.

We addressed concerns about the reliability of this process in three ways. Firstly, we standardised the physicians' and nurses' training by conducting only two training sessions for each group (one in each state), and the sessions were conducted by the same two investigators. Secondly, we conducted a quality control study to identify and then re-review the charts of the physician reviewers with the lowest and highest detection rates of adverse events. Thirdly, we conducted an in-depth reliability study.

\section{Definition of variables}

An adverse event was defined as an injury caused by medical management (rather than the disease process) that resulted in either prolonged hospital stay or disability at discharge. We required a confidence score of four or greater from the reviewing physician to indicate the presence of an adverse event. As with other studies, ${ }^{6}$ preventability was then independently judged by two study investigators (EJT and TAB), who were blinded to all hospital characteristics. An adverse event was considered preventable if it was avoidable by any means currently available unless that means was not considered standard care. All adverse events that contributed to the annual incidence were analysed for this report.

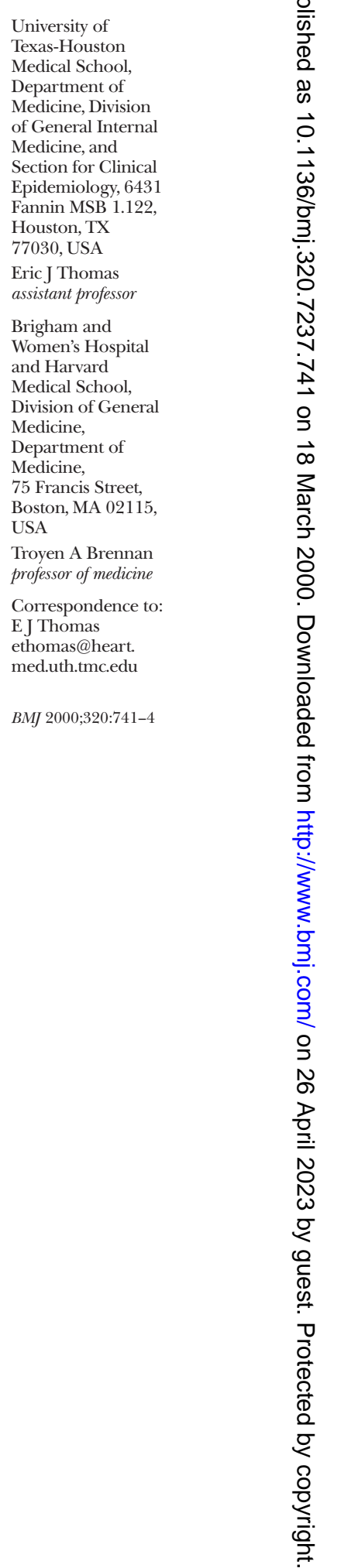


The patient characteristics used were sex, race (white and non-white), and payment method (uninsured, Medicare, Medicaid, private care or other, and managed care). To focus on adverse events among elderly patients, age was categorised as 16-64 years (nonelderly) and $\geqslant 65$ (elderly). Comorbid illness was measured with the Charlson comorbidity index. We also recorded diagnosis related group (DRG) level as a measure of case mix..$^{5}$ This variable was created by grouping DRGs into four levels according to the clinical likelihood that they would be associated with an adverse event. Data on age, sex, and payment method were obtained from the state discharge databases and confirmed by the chart reviewers. Patients' race and Charlson score were obtained using data from the medical record. Hospital characteristics were: size $(<8000$ discharges a year or $\geqslant 8000$ discharges a year), location (urban or rural), teaching status (major, minor, or non-teaching), and ownership (for profit, non-profit, or government).

Disability ratings were first made by the physician reviewers using the severity of injury scale of the National Association of Insurance Commissioners. ${ }^{7}$ Next, the two study investigators and a panel of adjusters for medical malpractice claims reviewed each case and reached consensus on a final score for each patient.

\section{Statistical analysis}

We report the rates of adverse events and preventable adverse events for elderly and non-elderly patients as the percentage of hospitalisations during which events were detected. If more than one adverse event was detected during a hospitalisation, only the event that caused the most disability was analysed. To avoid overrepresentation and underrepresentation of patients from particular types of hospitals, we report population estimates of adverse events. For each of the sample hospitals, we calculated weights by dividing the number of discharges of elderly or non-elderly patients during 1992 by the total number of records of elderly or non-elderly patients that were reviewed. Standard errors for the weighted rates were calculated, using weighted logistic regression models.

Logistic regression was used to determine if age was independently associated with preventable adverse events after other patient and hospital characteristics were adjusted for. Since we included hospital characteristics in the logistic regression models, the models analysed only those patients whose adverse events were due to management in a sampled hospital, as opposed to during an office visit before hospitalisation.

Variables in the model included hospital ownership, teaching status, size, location, and the patient characteristics of age ( $16-64$ and $\geqslant 65$ years), race, sex, payment method, DRG level, and Charlson score. We made adjustment for correlation of adverse events within hospitals by using the generalised estimating equation approach. ${ }^{8}$

\section{Results}

Thirteen hospitals in Utah and 15 in Colorado participated in the study. Nurses reviewed 4943 (98.9\%) of the 5000 sampled records in Utah and $9757(97.6 \%)$ of the 10000 records sampled in Colorado, representing $2.6 \%$ of all discharges in these states in 1992. Of these records, the nurses referred 854 (17.3\%) Utah records and 2014 (20.6\%) Colorado records to physicians for further review. The physicians reviewed $842(98.6 \%)$ of the referred Utah records and $1978(98.2 \%)$ of the referred Colorado records. The rest were classified as missing.

The demographic characteristics of the patients whose records were sampled were similar to the characteristics of all patients discharged in each state in $1992{ }^{4}$

Table 1 shows that the reviewers detected 241 adverse events (of which 132 were preventable) among non-elderly patients (aged 16-64 years) and 207 adverse events (of which 117 were preventable) among elderly patients (aged $\geq 65$ ). When these results were extrapolated to represent all discharges in each state in 1992, there were 8901 adverse events among non-elderly patients (incidence 2.80\% (SE 0.18\%)) compared with $7419(5.29 \%(0.37 \%))$ among elderly patients $(\mathrm{P}=0.001)$. For preventable adverse events, the incidence was also nearly twice as high in elderly patients: non-elderly patients had 5038 preventable adverse events (incidence 1.58\% (SE 0.14\%)) compared with $4134 \quad(2.95 \% \quad(0.28 \%))$ in elderly patients $(\mathrm{P}=0.001)$.

A greater proportion of the elderly patients who experienced preventable adverse events had permanent disability or death as a result than did the non-elderly patients $(8.66 \%$ (SE 2.75\%) $v \quad 5.80 \%$ $(2.11 \%)$ for permanent disability and $10.44 \%(2.96 \%) v$ $4.65 \%(1.94 \%)$ for death). However, these differences were not statistically significant (table 2 ).

The elderly patients had a higher incidence of several types of preventable adverse events (table 3). The incidence was significantly higher for preventable events related to medical procedure (such as thoracentesis or cardiac catheterisation) $(0.69 \%$ (SE 0.14\%) in elderly patients $v 0.13 \%(0.04 \%)$ in non-elderly patients), preventable adverse drug events $(0.63 \%$ $(0.14 \%) v 0.17 \%(0.05 \%))$, and preventable falls $(0.10 \%$ $(0.06 \%)$ v $0.01 \%(0.02 \%))$.

Table 1 Number and incidence of adverse events and preventable adverse events among patients discharged from hospitals in Utah and Colorado in 1992 by age group

\begin{tabular}{|c|c|c|c|c|c|c|c|}
\hline & \multicolumn{3}{|c|}{ Patients aged $16-64$ years } & \multicolumn{3}{|c|}{ Patients aged $\geqslant 65$ years } & \multirow[b]{3}{*}{$\begin{array}{l}\text { Difference in incidence } \\
\text { ( } P \text { value })\end{array}$} \\
\hline & \multirow[b]{2}{*}{$\begin{array}{l}\text { Unweighted No } \\
\text { of events* }\end{array}$} & \multicolumn{2}{|c|}{ Weighted events† } & \multirow[b]{2}{*}{$\begin{array}{l}\text { Unweighted No } \\
\text { of events* }\end{array}$} & \multicolumn{2}{|c|}{ Weighted events $\dagger$} & \\
\hline & & $\begin{array}{l}\text { No of } \\
\text { events }\end{array}$ & $\begin{array}{l}\text { Incidence } \\
(\% \text { (SE)) }\end{array}$ & & $\begin{array}{l}\text { No of } \\
\text { events }\end{array}$ & $\begin{array}{l}\text { Incidence } \\
(\% \text { (SE)) }\end{array}$ & \\
\hline All adverse events & 241 & 8901 & $2.80(0.18)$ & 207 & 7419 & $5.29(0.37)$ & 0.001 \\
\hline Preventable adverse events & 132 & 5038 & $1.58(0.14)$ & 117 & 4134 & $2.95(0.28)$ & 0.001 \\
\hline
\end{tabular}

${ }^{*}$ No of events noted in random sample of 15000 patient records.

†Extrapolation of unweighted results to represent all hospital discharges in Utah and Colorado in 1992. 
Table 2 Disability and death due to preventable adverse events among patients discharged from hospitals in Utah and Colorado in 1992 by age group*

\begin{tabular}{|c|c|c|c|c|c|}
\hline & \multicolumn{2}{|c|}{ Patients aged $16-64$ years } & \multicolumn{2}{|c|}{ Patients aged $\geqslant 65$ years } & \multirow[b]{2}{*}{$\begin{array}{l}P \text { value for difference } \\
\text { in percentages }\end{array}$} \\
\hline & No of events & $\begin{array}{l}\text { Percentage (SE) } \\
\text { of events }\end{array}$ & No of events & $\begin{array}{l}\text { Percentage (SE) } \\
\text { of events }\end{array}$ & \\
\hline Temporary disability & 4511 & $89.55(2.67)$ & 3344 & $80.89(3.72)$ & 0.053 \\
\hline Permanent disability & 292 & $5.80(2.11)$ & 358 & $8.66(2.75)$ & 0.383 \\
\hline Death & 234 & $4.65(1.94)$ & 432 & $10.44(2.96)$ & 0.08 \\
\hline All preventable adverse events & 5037 & 100 & 4134 & 100 & \\
\hline
\end{tabular}

*Results from random sample of 15000 patient records extrapolated to represent all hospital discharges in Utah and Colorado in 1992.

\section{Multivariate analyses}

After adjusting for the patient and hospital characteristics mentioned above, we found that age was not independently associated with preventable adverse events. The only patient characteristic associated with preventable adverse events was diagnosis related group (DRG) level. Compared with patients with DRG level 1 (the least complex DRG), patients with DRG level $2 \mathrm{had}$ an odds ratio of $7.8(\mathrm{P}=0.001)$, patients with $\mathrm{DRG}$ level $3 \mathrm{had}$ an odds ratio of $11.4(\mathrm{P}=0.0001)$, and patients with DRG level 4 had an odds ratio of $14.3(\mathrm{P}=0.0001)$ for suffering a preventable adverse event. Since DRGs are assigned to admissions retrospectively, a higher DRG level may indicate the presence of an adverse event during the admission in addition to, or instead of, more complex care. Therefore, we ran the model without the DRG level variable and found that age was still not independently associated with preventable adverse events.

\section{Discussion}

This population based study of hospitalised patients in Utah and Colorado found that elderly patients had a higher incidence of preventable adverse events, especially preventable adverse drug events, events related to medical procedures, and falls. They also tended to experience more permanent disability and death from these events, although the results were not statistically significant. We also found that, after adjustment for other patient and hospital characteristics, age was not an independent predictor of preventable adverse events.

This suggests that the elderly patients were not victims of age related discrimination but rather that their care was more complex. It is also likely that their time at risk and exposure to preventable adverse events was greater than younger patients. For example, the elderly patients could have received more drugs, had more procedures performed, and had longer lengths of stay in hospital than younger patients. In addition, elderly patients often do not present with typical signs and symptoms of diseases, thus making timely and accurate diagnoses more difficult; they take more drugs than younger patients; and they have impaired physiological compensatory mechanisms and are therefore more likely to be harmed by errors in care. ${ }^{9}$

\section{Comparison with other studies}

Other studies support these findings. The Harvard medical practice study found that elderly patients had a higher incidence of adverse drug events, falls, and events related to medical procedure. ${ }^{2}$ Steel et al found that the mean age of patients experiencing a severe preventable adverse event was 6.2 years greater than patients whose hospital course was uncomplicated. ${ }^{10}$ A study of 232 admissions to a Veterans Administration hospital found that the complication rate for the younger group $(<65$ years old) was $29 \%$ compared with $45 \%$ for the older group $(\geqslant 65) .{ }^{11}$ Another study of 185 veterans who were all aged over 75 (mean age 81) found an incidence of $38 \%$ for hospital acquired complications. ${ }^{12}$

When we focused on specific types of events, our results were consistent with those of others, who found that elderly patients have more adverse drug events and falls. One study reported the incidence of adverse drug events to be $14.8 \%$ among hospitalised elderly patients (mean age 78.2).$^{13}$ This figure is much higher than the reported rate of adverse drug events in patients of all ages from other studies. ${ }^{6}{ }^{14}$ More detailed comparisons cannot be made because of the use of different methods to detect, and different definitions of, adverse drug events. The literature on falls among elderly people is large, reflecting the importance of this problem. However, this research is mostly focused on elderly people residing in nursing homes or at home. In one study of hospitalised patients of all age groups, Morgan et al found that the incidence of falls in elderly patients was $1.9 \% .^{15}$ Once again, this generally

Table 3 Number and incidence of preventable adverse events among patients discharged from hospitals in Utah and Colorado in 1992 by type of event and age group*

\begin{tabular}{|c|c|c|c|c|}
\hline \multirow[b]{2}{*}{ Event type } & \multicolumn{2}{|c|}{ Patients aged $16-64$ years } & \multicolumn{2}{|c|}{ Patients aged $\geqslant 65$ years } \\
\hline & No of events & $\begin{array}{c}\text { Incidence } \\
\text { (\% (SE)) }\end{array}$ & No of events & $\begin{array}{c}\text { Incidence } \\
\text { (\% (SE)) }\end{array}$ \\
\hline Diagnostic & 697 & $0.22(0.05)$ & 379 & $0.27(0.09)$ \\
\hline Operative: & 2411 & $0.76(0.10)$ & 1383 & $0.99(0.17)$ \\
\hline Technical & 1341 & $0.42(0.07)$ & 327 & $0.23(0.09)$ \\
\hline Bleeding & 643 & $0.20(0.05)$ & 542 & $0.39(0.11)$ \\
\hline Wound infection & 79 & $0.02(0.02)$ & 0 & \\
\hline Non-wound infection & 78 & $0.02(0.02)$ & 157 & $0.11(0.07)$ \\
\hline Other wound problem & 101 & $0.03(0.03)$ & 33 & $0.02(0.05)$ \\
\hline Other technical problem & 0 & & 20 & $0.01(0.06)$ \\
\hline Pulmonary embolism & 0 & & 43 & $0.03(0.05)$ \\
\hline Cerebrovascular accident & 0 & & 0 & \\
\hline Congestive heart failure & 0 & & 54 & $0.04(0.05)$ \\
\hline Deep vein thrombosis & 75 & $0.02(0.02)$ & 0 & \\
\hline Acute myocardial infarction & 0 & & 0 & \\
\hline Pneumonia & 0 & & 37 & $0.03(0.05)$ \\
\hline Other non-technical & 52 & $0.02(0.02)$ & 90 & $0.06(0.06)$ \\
\hline Missing & 43 & $0.01(0.02)$ & 80 & $0.06(0.05)$ \\
\hline Fractures & 23 & $0.01(0.02)$ & 0 & \\
\hline Anaesthesia & 101 & $0.03(0.03)$ & 0 & \\
\hline Post partum & 341 & $0.11(0.04)$ & 0 & \\
\hline Neonatal & 44 & $0.01(0.02)$ & 0 & \\
\hline Medical procedure & 421 & $0.13(0.04)$ & 963 & $0.69(0.14) \dagger$ \\
\hline Drug & 543 & $0.17(0.05)$ & 889 & $0.63(0.14) \dagger$ \\
\hline Therapeutic & 284 & $0.09(0.04)$ & 280 & $0.10(0.06)$ \\
\hline Fall & 20 & $0.01(0.02)$ & 136 & $0.10(0.06) \dagger$ \\
\hline Other & 154 & $0.05(0.03)$ & 103 & $0.07(0.06)$ \\
\hline
\end{tabular}

${ }^{*}$ Results from random sample of 15000 patient records extrapolated to represent all hospital discharges in Utah and Colorado in 1992.

†Significantly higher than incidence in younger patients $(P<0.05)$. 


\section{What is already known on this topic}

Only one large population based study has found a higher rate of preventable adverse events in elderly people

\section{What this study adds}

Patients aged $\geqslant 65$ experienced more preventable adverse events than those aged $<65$

Preventable adverse drug events, falls, and events related to medical procedure were more common in the elderly patients

After adjustments were made for complexity of care and other patient and hospital characteristics, age was not an independent correlate of preventable adverse events

corroborates our finding, but detailed comparisons are not possible because Morgan et al did not require the fall to prolong hospital stay, as our definition of an adverse event did. In fact, they detected only three falls that prolonged hospital stay.

We also found more preventable adverse events related to medical procedures in the elderly patients. In our study this was a heterogeneous group of procedures (thoracentesis, central venous catheterisation, bronchoscopy, cardiac catheterisation, etc) and complications (bleeding, infections, pneumothorax, etc). This heterogeneity and the relatively small sample size limit specific comparisons of complications related to procedures described in other studies and also limit the conclusions to be drawn from our observation.

\section{Limitations of study}

Limitations of our study include the moderate reliability of judgments about adverse events $(\kappa=0.4)$, our method's reliance on documentation in medical records, our counting only those events that prolonged hospital stay or caused disability at discharge, our use of general internists and family practitioners as reviewers instead of specialists, and the non-random selection of hospitals. We could not quantify the degree to which a preventable adverse event caused death sooner than a patient's underlying disease process would have led to death. Finally, we did not directly measure and adjust for variables that may have influenced the rate of preventable adverse events in the elderly patients, such as number of procedures, number of drugs, and length of stay. However, we were able to control for comorbid illnesses, and we used a surrogate marker (DRG level) for complexity of care.

\section{Conclusions}

We found that elderly patients suffered more preventable adverse events in hospital than younger patients, possibly because of the increased complexity of their care. Additional research and prevention efforts should focus on adverse drug events, falls, and operative complications.

Contributors: EJT supervised data collection, conducted data analysis and interpretation, and wrote the paper. TAB was principal investigator, supervised data collection and analysis, interpreted data, and assisted in writing the paper. Mr Tim Zeena performed statistical programming. EJT is guarantor for the study.

Funding: The study was funded by the American Association of Retired Persons and the Robert Wood Johnson Foundation. EJT is a Robert Wood Johnson Foundation generalist physician faculty scholar.

Competing interests: None declared.

1 Kohn LT, Corrigan JM, Donaldson MS, eds. To err is human. Building a safer health system. Washington, DC: National Academy Press, 1999

2 Leape LL, Brennan TA, Laird NM, Lawthers AG, Localio AR, Barnes BA, et al. The nature of adverse events in hospitalized patients. Results of the Harvard medical practice study II. N Engl J Med 1991;324:377-84.

3 Profile of older Americans. www.aoa.dhhs.gov/aoa/stats/profile (cited 27 Nov 1998)

4 Thomas EJ, Studdert DM, Burstin HR, Orav EJ, Zeena T, Williams EJ, et al. Incidence and types of adverse events and negligent care in Utah and Colorado in 1992. Med Care (in press).

5 Brennan TA, Leape LL, Laird NM, Hebert L, Localio AR, Lawthers AG, et al. Incidence of adverse events and negligence in hospitalized patients. Results of the Harvard medical practice study I. $N$ Engl J Med 1991:324:370-6

6 Bates DW, Cullen DJ, Laird N, Petersen LA, Small SD, Servi D, et al. Incidents of drug adverse events and potential adverse drug events. Implications for prevention. ADE Prevention Study Group. JAMA 1995;274: 29-34

7 Sowka M, ed. National Association of Insurance Commissioners, malpractice claims: final compilation. Kansas City, MO: National Association of Insurance Commissioners, 1980.

8 Diggle PS, Liang K, Zeger SL. Analysis of longitudinal data. Oxford: Clarendon Press, 1995

9 Resnic NM, Marcantonio ER. How should clinical care of the aged differ? Lancet 1997;350:1157-8.

10 Steel K, Gertman PM, Crescenzi C, Anderson J. Iatrogenic illness on a general medical service at a university hospital. $N$ Engl J Med 1981;304:638-42.

11 Jahnigen D, Hannon C, Laxson L, LaForce FM. Iatrogenic disease in hospitalized elderly veterans. J Am Geriatr Soc 1982;30:387-90.

12 Becker PM, McVey LJ, Saltz CC, Feussner JR, Cohen HJ. Hospitalacquired complications in a randomized controlled clinical trial of a geriatric consultation team. JAMA 1987;257:2313-7.

13 Gray SL, Sager M, Lestico MR, Jalaluddin M. Adverse drug events in hospitalized elderly. J Gerontol A Biol Sci Med Sci 1998;53:M59-63.

14 Classen DC, Pestonik SL, Evans SR, Loyd JF, Burke JP. Adverse drug events in hospitalized patients. JAMA 1997;277:301-6.

15 Morgan VR, Mathison JH, Rice JC, Clemmer DI. Hospital falls: a persistent problem. Am J Public Health 1985;75:775-7.

(Accepted 18 February 2000)

\section{One hundred years ago \\ The war in South Africa: "Comforts" and luxuries}

The small luxuries and comforts which count for so much in the mind of the public when it turns its attention to hospitals, were provided in abundance. Of tobacco, too, there was an ample supply. The open-air method of treatment which the climate permits, and which has been so widely and wisely adopted in the military hospitals, allows of free use of tobacco in wards without annoyance to non-smokers. Tobacco has a very real value in the treatment of such cases as abound in military hospitals in time of war. A full supply of tobacco for smoking, in whatever form it might be preferred, would in the field hospitals and dressing stations be second only in value to morphine, and would very often most advantageously replace it. Men waiting their turn to be dressed after they are brought down from the fighting line often positively crave for tobacco, and it acts as a most efficient and harmless anodyne. A box of cigars or cigarettes would often give as much relief as the hypodermic syringe, and fit a man far better to stand a rough journey from the dressing station into the field or stationary hospital. The value of tobacco is recognised, but still not recognised enough.

(BMJ 1900;i:774) 